\title{
3. What has federalism ever done for us? ${ }^{1}$
}

\section{The Hon Anna Bligh MP, Premier of Queensland}

In April 2008, our new Prime Minister gathered together 1000 of our country's best and brightest to imagine the Australia we could be in 2020. As I left Canberra on that cold Sunday afternoon, I was both inspired and alarmed. Inspired by the wealth of ideas and the many new voices that had been unearthed by the process and alarmed that the most recurring theme and, without doubt, the most popular idea was the abolition of the states.

Here were some of the country's brightest, most educated, most experienced and publicly engaged thinkers cheering rapturously at a throwaway line from Tim Fischer about getting rid of the states. It gave me real pause for thought.

A century ago, as the fathers of the federation shaped the constitution, the preservation and protection of the states were pivotal to their deliberations, and yet today there seems to be a headlong, popular rush to abandon them. I was struck by how comprehensively John Howard had demonised the states, but I was also acutely aware that this alone could not explain the phenomenon.

At the very least, the summiteers' reaction articulated a real sense of disappointment and frustration with many key areas of social service provision. States ignore this at their peril.

So, a century on from federation, against a backdrop of an emerging cooperative federalism and fresh from a meeting of COAG, I thought it would be useful here to reflect on federalism as a form of government and contemplate the future of our own federation. In doing so, I intend to mount a spirited defence of the federation.

I will, no doubt, be accused of self-interest in this respect; I note that the wheels of constitutional change turn at a glacial pace in this country and any radical change in the federation is unlikely to happen during my political career. So, I speak as a citizen as much as a premier and I caution against the inevitable, perhaps intoxicating, rush to simple solutions.

In essence, I believe that, in a country of 21 million people, spread across 7.6 million square kilometres, providing services to people in some of the great cities of the world and some of the most remote places on Earth, a federation of states is the most effective way to govern, to manage and to provide services. 


\section{What has federalism ever done for us?}

A century ago, Australia's colonies were able to design the government they wanted. They examined governments around the world and they chose a federation. They were not alone in so choosing. The United States, Switzerland and Canada were among the nations that had already decided on a federation. Looking back over 107 years of federalism in Australia, we might well ask: what has federalism ever done for us?

Well, how about this: federalism divides and limits power, providing checks and balances that protect individuals, mitigate against an overly powerful central government and assist accountability. Federalism allows for coordinated national action on issues of national importance, such as responses to natural disasters like cyclones. It also encourages healthy competition and creativity between the states and territories, both of which lead to improvements in performance, efficiency and outcomes.

For example, consider how uncompetitive our state tax arrangements would be if there was not a healthy competition between states to lower the tax burden in every budget. Federalism recognises the distinctive nature and identity of the regions of Australia through the states and territories, thereby allowing for policies and services to be tailored to the different needs of different people and communities across vast and varied country.

Federalism offers a number of other advantages, as detailed in a report by Anne Twomey and Glenn Withers for the Council for the Australian Federation in 2007. They point out that many Australians see our structure of government as old-fashioned, cumbersome and inefficient. Yet, in other places, federalism is viewed as modern, flexible and efficient in dealing with the increasing pressures faced by communities. This report shows that, when compared with centralised, unitary governments, federated structures such as Australia have:

- more efficient governments

- higher rates of economic growth

- $\quad$ higher per capita GDP.

Further, their research demonstrates that increasing centralisation threatens these benefits.

The foundation of our current prosperity as a nation is built on significant economic, social and environmental reforms, negotiated and put in place through our federal structure. As the report demonstrates, of the G8 nations - the countries with the greatest economies in the world-four are federations and seven have at least three tiers of government. The success of federations - and of countries with three tiers of government - is not transitory, as Twomey and Withers state: 'In the past 50 years, federations have consistently out-performed 
unitary systems in economic terms...the more centralised the federation, the better the performance.'

\section{What have the states ever done for us?}

If some Australians question the value of federalism, I think many more might ask: what have the states ever done for us? For most Australians, most of the time, most of the government services they use are delivered by the states, such as the schools their children attend, the public hospitals where they seek emergency care and surgery, the roads they drive on, the buses and trains they catch, the clean water provided to their homes.

Why is it that the states deliver most services, even though the Commonwealth funds at least some of them? One reason is that our federation is built on the principle of subsidiarity - the idea that matters should be dealt with, and services provided by, competent government closest to the community.

Given the scale usually required to deliver universally available services, that generally means the state and territory governments, and in some cases it means local government. Under the subsidiarity principle, matters of national interest, such as defence, and areas that require a nationally equitable approach across state borders, such as income support, should sit with the national government.

Similarly, cross-jurisdictional matters or areas where harmonisation is required, such as corporation laws, and where economies of scale can be derived, also sit naturally with the national government. However, where services need to be delivered in person or tailored to local circumstances, other levels of government are best placed to manage service delivery.

And we should remember that these large, and sometimes challenging, service delivery systems deliver some extraordinary results across our country. In Australia today, 2.268 million children will be taught in a state school classroom and about 120000 people will be treated as non-admitted patients in public hospitals. In Queensland today, some 478000 children are being educated in state schools and more than 28800 people will be treated as non-admitted patients in public hospitals.

\section{The system isn't perfect}

However, neither the federation nor the states are perfect. The problems have been well documented: creeping centralism in all areas of public policy and service delivery; complexity and confusion about the roles and responsibilities of the Commonwealth and the states; a system that can be bureaucratic, cumbersome and slow to respond to cross-jurisdictional or emerging issues; duplication of services, wastage of funds, cost-shifting and buck-passing; and financial arrangements that have produced an extreme vertical fiscal imbalance. 
No wonder there is frustration and disappointment at service delivery failures. Government doesn't always deliver services well, on time, on budget or to expectation. There have been some awful failures, as Queensland experienced recently with the poor maintenance of nurses' accommodation in the Torres Strait, with the resultant threat to the safety and security of our staff in an isolated part of the state, which, in turn, has led to problems in recruiting and retaining qualified staff.

I understand, and share, people's frustration and I have to say the states, including my own, can do much better on service delivery. Accompanying this is a belief that another level of government - in most cases, the federal government - could do a better job, as we saw from the preliminary results of a survey on constitutional values by Griffith University, which were published in The Australian on 3 July 2008. The survey of 1200 voters showed that half of them believed the Commonwealth was the level of government that was most effective at doing its job; just under 20 per cent nominated local government; and just over 18 per cent nominated the states. And just over 79 per cent thought the Commonwealth should get involved in issues that were the responsibility of state governments.

This rush to a seemingly simple solution is underpinned, in my view, by the fact that most people have limited experience of the Commonwealth as a direct service provider. They are just blindly hoping the Commonwealth will do a better job. They are also apparently in the grip of collective amnesia about the Commonwealth's record when it does actually deliver services. So let's stop for a moment and remember:

- the kerosene baths for frail aged people in a nursing home under the purview of a Commonwealth department

- the long-running and expensive saga of defence procurement, such as the Collins-class submarines

- unjust and unlawful detentions by an immigration department that was assessed as incompetent by the Commonwealth itself.

Contemplate the alternative. Imagine the lack of coherence if all of Australia's schools, more than 9500 in all, were run out of Canberra. Consider the challenge for a mum in Broome seeking to influence a federal Education Minister from Melbourne about the toilet block at the local public school, or worse still, imagine if schools were the responsibility of some 700 local governments. I raise these examples not as a partisan political attack or as a Canberra-bashing exercise but to highlight that service delivery problems are not the exclusive preserve of any one level of government, but rather that they are endemic to the business of delivering services. 


\section{Appetite for change}

I am not alone in identifying the problems with our federation and the need for reform. Debate about federalism, which cooled after the failure of the republic referendum, has been rekindled in the past few years. We've had some significant contributions from, among others, former premiers Peter Beattie and Steve Bracks, the states and territories through the Council for the Australian Federation, Kevin Rudd as Opposition Leader and as Prime Minister, the Business Council of Australia and delegates to the Australia 2020 Summit and the Queensland 2020 Summit. I think it's fair to say there is widespread agreement that we need reform.

But before we start tearing up our constitution, or abolishing our states, let's acknowledge that federations have much to offer. Let's acknowledge that there is a global move towards federalism rather than away from it. Countries such as Spain, Belgium and South Africa, which had been unitary, have adopted federal structures, thereby maintaining some central control while also permitting some regional control. The United Kingdom is creating legislatures and devolving responsibilities in Scotland, Wales and Northern Ireland. And of course there is the European Union, a federation of sovereign nations that more often than not also have very strong provincial governments. So, let's keep our federation but let's make it work better.

\section{Some proposals}

I'd like to offer some proposals to reinforce and reinvigorate our system. My proposals are built on three key beliefs:

- a belief in the principle of subsidiarity

- a belief in the need for clear roles and responsibilities - and in many major services of importance, shared responsibilities, based on changing needs, challenges and opportunities facing our citizens

- a belief that the Commonwealth and the states must be willing to both assume and surrender responsibilities.

I can best articulate these beliefs by explaining how they would apply to three key policy areas, and to Commonwealth-state financial relations. I will start with the roles and responsibilities in two key human services that are in great need of reform - that is, education and training, and health - and, finally, move on to climate change, a new public policy challenge that will have an enormous impact on each of us.

\section{Education and training}

As a former education minister and as a parent, I know that education is the key that unlocks a child's potential. Education, skills, innovation-these are the keys to our individual and collective prosperity. 
Given their importance, education and training are the first policy areas in which I propose reform of state and federal relations. Some of you might be aware that in the lead-up to the Australia 2020 Summit, I proposed the introduction of a full national curriculum progressively from the beginning of the 2010 school year, supported by a new national curriculum authority incorporating the state, Catholic and independent sectors.

Here, I want to go further. In a globalised economy, with an increasingly mobile population, in the midst of a skills shortage, we need greater consistency in our education and training system. Currently, we have a mishmash of inconsistent responsibilities and accountability requirements.

In early childhood education and care, the states are largely responsible for licensing and regulating childcare centres, which the Commonwealth funds and accredits and with its own quality-assurance system attached. The end result is massive duplication, with childcare centres having to report on policies and practices to two levels of government. Notwithstanding the Commonwealth's recent commitment to universal access to preschool for all four year olds, currently the states are the primary funders and regulators of preschool services and accredit the programs that are used.

In primary and secondary education, the states provide public education, but regulate private schools. However, we fund, register teachers and approve the curriculum for both sectors. Meanwhile, the Commonwealth chips in some funding for public schools, most of the funding for private schools and has its own accountability requirements for both sectors, in addition to those of the states.

In vocational education and training, states regulate the training system, purchase training from public and private training providers and provide training through TAFE and community colleges. The Commonwealth provides about one-quarter of training funds and also subsidises employers to take on apprentices. And universities are created under state legislation, get most of their funding from the Commonwealth and face the accountability requirements of both. It's time for a radical rethinking of roles and responsibilities.

One option is for the states to take primary responsibility for service delivery in early childhood and care as well as school education and for the Commonwealth to assume primary responsibility for delivery of post-school qualifications in the vocational education and training (VET) system and universities. I am not proposing a complete takeover of early childhood and school education by the states. The Commonwealth could usefully retain lead responsibility for setting overall national goals and a national curriculum. But the delivery would be the responsibility of the states, as provider in the public system and regulator in the private system. 
I think it's time for us to view early childhood and school education as one seamless system, whether it is publicly or privately provided. And surely the quality of care and education provided in all early childhood centres and schools should be the responsibility of one level of government. Similarly, responsibilities for post-secondary education and training should be reformed.

One of the key points of agreement at the Australia 2020 Summit was that we should develop a seamless national economy. Given the importance of skilled labour to our economy, surely this must mean streamlining our post-school education system. As with early childhood and school education, we need to see this system as a whole. Making the Commonwealth solely responsible for VET and universities would be a major step in delivering the skilled workforce we need as a nation. Importantly, it would also significantly improve the efficiency of our university and VET providers and reduce red tape and major duplication in financial and performance accountability requirements of the state and federal governments. It will also increase the national and international portability of the skills of our workforce.

\section{Health}

All states face significant challenges in delivering health services. Some of Queensland's challenges are unique. Each week, up to 1800 extra people arrive in our state and contribute to surging demand. The majority of residents live outside the capital, some in remote communities and some in regional centres such as Cairns, which is further away from Brisbane than Melbourne.

We have boosted spending on our health system, investing more than $\$ 10$ billion over five years. But over the past 10 years under the Howard Government, federal funding for our public health system fell from 50 to about 35 per cent. Frankly, we are struggling to keep pace with growth and demand.

If Queensland's current rates of population growth, economic growth and public health spending continue unabated, by 2042 our public health spending will consume the entire state budget. This is not in the public interest. That's my motivation for proposing some major changes in the way we manage health, as a nation.

In our submission to the National Hospitals and Health Reform Commission, we suggest key reforms. In my view, states should be responsible for health services that are likely to require an integrated service delivery response. For example, many of the problems we encounter in relation to Indigenous health in remote communities cannot be addressed solely through the health system; there is sometimes a housing issue, sometimes a need for upgraded water supplies or better sewerage systems, which, of course, the state delivers.

This means the states should be responsible for Indigenous health. Queensland agrees with the commission that the states should continue to be responsible for 
acute-care services - those that require hospital admissions. However, we need the Commonwealth to take responsibility for things that are making the job of running hospitals that much harder. At the moment, there are people waiting in hospital emergency wards who really just need to see a GP, and a shortage of nursing home beds - controlled by the Commonwealth - means that every day an average of 468 Queenslanders who need a nursing home bed are in fact in acute-care beds in public hospitals and Queensland bears the extra cost of almost $\$ 400000$ a day.

The problem is that public hospitals are run by state governments and nursing homes are overseen by the Commonwealth. There is no imperative, no incentive for the two sectors to work together. Queensland's submission proposes that the Commonwealth should pay the states the full cost of providing such services in a hospital. I'm confident that pressure on the Commonwealth's hip-pocket nerve would lead to a rapid appreciation of the need to fix these anomalies. The National Health and Hospitals Reform Commission is a good example of the way in which we can maturely and systemically renegotiate roles and responsibilities to achieve better health care for all Australians.

\section{Climate change}

Professor Ross Garnaut's report to the government-The Garnaut Climate Change Review - examines, for the first time, the costs of climate change to Australia. His findings will be challenging. The report doesn't offer easy solutions. Climate change is the most critical challenge facing Australia and the world. We must get it right. And given the embryonic nature of policy making regarding climate change, we have the chance to get it right from the very beginning rather than reworking an existing system. We have the chance to ensure the different levels of government do not end up tripping over each other. We must ensure our federation is sufficiently responsive, agile and coordinated to deal with the complex issues relating to challenges from climate change.

\section{Opportunity for change}

My argument for reform is not about the states, it's about the health and sustainability of our federation. It is, by no means, a perfect system. But, to misquote Winston Churchill, just 'a little federalism is the worst form of governance, except for all the others'.

One hundred and eleven years ago, a proponent of federalism, Sir Isaac Isaacs, spoke of the colonies being at a point of great tension as they considered whether to form a federation. I think we are at another point in our history where there is great tension around how we work together. Our nation has evolved and our world has changed greatly since 1901 but our federal system and our constitution have not. We are at a point of great opportunity, with governments of the same political persuasion in power across Australia, a Prime Minister committed to a 
new federalism and state and territory leaders who want a real partnership. We have an appetite for change. There is also an opportunity for change - a once-in-a-generation opportunity. Let's make the most of it.

\section{ENDNOTES}

${ }^{1}$ This essay was originally presented as an ANZSOG Public Lecture on 4 July 2008. 